\title{
Lakon Brubuh Maèspati: Intepretasi Ulang Nilai Kesetiaan
}

\author{
Joko Laras Moyo \\ Jurusan Pedalangan, Fakultas Seni Pertunjukan, Institut Seni Indonesia Yogyakarta \\ Email: jokolaras@gmail.com
}

\begin{abstract}
Lakon Brubuh Maèspati: The work of the puppet performance is aimed at presenting one of the stories in the Maespati kingdom, which is rarely performed in Yogyakarta. This work is entitled Brubuh Maèspati. The play Brubuh Maèspati is a piece of the puppet plays that tells Harjunasasrabahu, Dewi Citrawati, Suwanda, and Dasamuka. The concept of sanggit of Soetarno et al. used as a framework for working on the play Brubuh Maèspati. Sanggit means the mastermind's creativity related to interpretation and the cultivation of Pakeliran elements to achieve the aesthetic stability of puppet shows. The cultivation of Brubuh Maèspati begins with watching and reading plays related to the kingdom of Maespati. There were three plays which were chosen to be the basis for interpreting the values of loyalty, namely Actions Sumantri Ngèngèr, Dasamuka Gladhak, and Brubuh Maèspati. Then do the play, work on the characters, work on the scene, and work on musical accompaniment according to the Pakeliran structure of Yogyakarta. Brubuh Maèspati is a reinterpretation of the value of loyalty that is communicated by the plays that tell the Kingdom of Maespati.
\end{abstract}

Keywords: Brubuh Maèspati; sanggit; garap; loyalty

\begin{abstract}
Abstrak
Karya pergelaran wayang ini bertujuan menyajikan kembali salah satu kisah di kerajaan Maespati, yang jarang dipergelarkan di Yogyakarta. Karya ini diberi judul Brubuh Maèspati. Lakon Brubuh Maèspati merupakan sanggit dari lakon-lakon wayang yang mengisahkan Harjunasasrabahu, Dewi Citrawati, Suwanda, dan Dasamuka. Konsep sanggit Soetarno dkk. dipakai sebagai kerangka pikir dalam menggarap lakon Brubuh Maèspati. Sanggit berarti kreativitas dalang yang berhubungan dengan penafsiran dan penggarapan unsur-unsur pakeliran untuk mencapai kemantapan estetik pertunjukan wayang. Penggarapan Brubuh Maèspati dimulai dengan menonton dan membaca lakon-lakon yang berhubungan dengan kerajaan Maespati. Ada tiga lakon yang dipilih menjadi landasan dalam menafsir nilai kesetiaan yaitu lakon Sumantri Ngèngèr, Dasamuka Gladhak, dan Brubuh Maèspati. Selanjutnya dilakukan garap lakon, garap tokoh, garap adegan, dan garap iringan karawitan sesuai dengan struktur pakeliran Yogyakarta. Brubuh Maèspati merupakan interpretasi ulang nilai kesetiaan yang dikomunikasikan oleh lakon-lakon yang mengisahkan Kerajaan Maespati.
\end{abstract}

Kata kunci: Brubuh Maèspati; sanggit, garap, kesetiaan 


\section{Pendahuluan}

Pada mulanya tertarik pada kisah kehancuran Negara Maespati karena rajanya terlalu menuruti permintaan sang istri seperti tertulis dalam buku Nonton Wayang dari Berbagai Pakeliran karya R.M Pranoedjoe Poesponingrat (2008). Ketertarikan ini kemudian berlanjut menjadi keinginan mempergelarkan kisah tersebut dalam sebuah pergelaran wayang. Ketertarikan ini didasari oleh adanya fenomena bahwa kisah kehancuran Negara Maespati seperti diceritakan dalam Lakon Bedhah Maèspati atau Arjunasasrabahu Léna jarang dipergelarkan di wilayah Yogyakarta. Lakon ini jarang dipertunjukkan di beberapa bagian wilayah Yogyakarta rupa-rupanya disebabkan adanya mitos larangan yang hidup di Yogyakarta (Sutejo, Sugati, dan Margiono, 12 September 2017).

Selain karena alasan jarangnya lakon Bedhah Maèspati dipergelarkan, alasan lain ketertarikan pengkarya untuk menggarap lakon ini disebabkan oleh banyak pesan moral yang terkandung dalam cerita tersebut yang dapat disampaikan kepada khalayak. Berdasarkan pengamatan dapat dikatakan bahwa pesan moral yang dikomunikasikan lakon Bedhah Maèspati antara lain adalah nilai kesetiaan. Pesan kesetiaan yang diterima dari lakon Bedhah Maèspati inilah yang akan diinterpretasi ulang dan direalisasikan oleh pengkarya dalam lakon Brubuh Maèspati.

\section{Kisah-Kisah di Kerajaan Maespati dalam Sumber Lisan dan Tulisan}

Lakon-lakon yang berhubungan dengan Maespati pernah diceritakan dalang Senior di Surakarta dan Yogyakarta seperti lakon Suwanda Gugur Ki Nartosabdo (1970), lakon Sumantri Ngèngèr Ki Manteb Sudarsono (2004), lakon Banjaran Ramabargawa Ki Hadi Sutikno (2009), lakon Wisnu Ratu Ki Timbul Hadiprayitno (2010), lakon Sumantri Ngèngèr Ki Purba Asmara (2012), lakon Dasamuka Gladhak Ki Catur Benyek Kuncoro (2016), lakon Brubuh Maèspati Ki Margiono (2016). Berikut ini dipaparkan ringkasan cerita dari lakon-lakon yang telah dipergelarkan oleh para dalang tadi.

Lakon Suwanda Gugur karya Ki Nartosabdo (1970) menceritakan Patih Suwanda gugur melawan
Dasamuka yang marah karena kemahnya dibanjiri oleh luapan Samudra Minangkalbu yang dibendung tubuh Prabu Harjunasasrabahu. Pembendungan samudra tersebut atas permintaan Dewi Citrawati permaisuri Prabu Harjunasasrabahu. Gugurnya Patih Suwanda, para prajurit, dan permaisuri serta seluruh selirnya menimbulkan kemarahan Prabu Harjunasasrabahu. Dasamuka dilabrak dan terjadi peperangan diantara keduanya. Dasamuka kalah kemudian diseret oleh Prabu Harjunasasrabahu. Resi Pulasta, eyang buyut Dasamuka memohon maaf kepada Prabu Harjunasasrabahu atas kesalahan cicitnya. Prabu Harjunasasra bersedia memberikan maaf dengan syarat Resi Pulasta bersedia menghidupkan kembali semua permaisuri dan prajuritnya yang mati. Akan tetapi Patih Suwanda tidak bisa dihidupkan karena sudah menjadi ajalnya.

Lakon Wisnu Ratu Karya Ki Timbul Hadiprayitno (2010) menceritakan kelahiran Patih Suwanda putra Resi Suwandagni dengan Endhang Yomani di Pertapaan Jatisrana. Sukma Sang Hyang Suwanda menitis pada jabang bayi dalam kandungan Endhang Yomani. Sang Hyang Soka kecewa mengetahui peristiwa tersebut. Ia menunggu di pangrantunan karena belum mendapatkan tempat untuk menitis. Bathara Karung Kala mengetahui bahwa putra Resi Suwandagni adalah titisan Sang Hyang Suwanda. Ia lalu segera membunuh bayi itu dengan cara menggigit lehernya hingga tewas. Dewi Sri Kembang menghidupkan kembali putra Endhang Yomani dan memberi nama Raden Suwanda. Oleh Resi Suwandagni anaknya itu diberi nama Bambang Sumantri.

Lakon Sumantri Ngèngèr karya Ki Manteb Sudarsono (2004) menceritakan pengabdian Sumantri kepada Harjunasasrabahu, raja Negara Maespati. Dalam lakon ini diceritakan Sumantri diutus oleh Prabu Harjunasasrabahu untuk melamar Dewi Citrawati dari negara Magada. Negara Magada waktu itu sedang dalam cengkraman Prabu Darmawasesa, raja Widarba. Sumantri berhasil mengalahkan Prabu Darmawasesa. Prabu Darmawasesa bersedia menjadi raja telukan Negara Maespati dan memberikan putri dhomas (delapan ratus orang putri). Prabu Citrasena, adik Dewi Citrawati, raja Magada mengijinkan Dewi Citrawati diboyong ke Maespati. Sebelum sampai Maespati, Sumantri mengirimkan surat tantangan kepada 
Prabu Harjunasasrabahu. Isi surat menyatakan bahwa Sumantri bersedia menyerahkan Dewi Citrawati asal Prabu Harjunasasrabahu bisa mengalahkannya. Prabu Harjunasasrabahu menanggapi tantangan Sumantri. Ia berhasil dikalahkan oleh Prabu Harjunasasrabahu. Setelah diboyong ke Maespati, Dewi Citrawati meminta agar Prabu Harjunasasrabahu memindah Taman Sri Wedari dari Kahyangan Untara Segara ke Maespati. Harjunasasrabahu memenuhi permintaan Citrawati. Ia memerintah Sumantri untuk memindahkan taman tersebut. Sumantri menyanggupinya. Sumantri merasa kesulitan. Sukasrana datang membantu Sumantri dan berhasil memindahkan Taman Sri Wedari ke Negara Maespati. Dewi Citrawati ketakutan ketika melihat Sukasrana yang berwujud raksasa kerdil berada di Taman Sri Wedari. Harjunasasra memerintahkan Sumantri untuk membunuh raksasa kerdil itu. Cerita yang hampir sama juga pernah dipentaskan Ki Manteb Sudarsono dalam lakon Dasamuka Glèdhèg (Prasetya, 2004). Walau judul lakonnya Dasamuka Glèdhèg tetapi Ki Manteb Sudarsono lebih menekankan pada tokoh Sukrasana (Prasetya, 2004).

Lakon Sumantri Ngèngèr karya Ki Purbo Asmoro (2012) menceritakan perjalanan hidup Sumantri yang bercita-cita ingin mengabdi di Negara Maespati. Pengabdian Sumantri akan diterima jika ia dapat memboyong Dewi Citrawati dari Negara Magada. Persyaratan tersebut dipenuhi oleh Sumantri dengan bantuan adiknya Sukasrana. Dewi Citrawati berkeinginan untuk membuktikan kesaktian Harjunasasra. Sumantri bersedia memenuhi keinginan Dewi Citrawati dengan mengirimkan surat tantangan perang. Harjunasasra mengalahkan Sumantri dan sebagai penebus kekalahannya Sumantri diminta memindahkan Taman Sri Wedari ke Negara Maespati. Sukasrana datang membantu Sumantri dan berhasil memindahkan Taman Sri Wedari ke Negara Maespati. Dewi Citrawati ketakutan ketika melihat Sukasrana, seorang raksasa kerdil ada di Taman Sri Wedari. Harjunasasra memerintahkan kepada Sumantri untuk membunuh raksasa kerdil itu. Sumantri menyuruh Sukasrana agar pulang ke pertapaan Jatisrana, namun Sukasrana menolak. Sumantri menarik keris menakut-nakuti Sukasrana. Di akhir cerita, Sukasrana mati dengan menubruk keris yang dibawa Sumantri. Mengetahui Sukasrana mati, Resi Suwandagni mengutuk bahwa masa kejayaan Prabu Harjunasasrabahu tidak akan lama.

Lakon Dasamuka Gladhak yang dipergelarkan Ki Catur Benyek Kuncara di Sasana Hinggil Dwi Abad (2016) menceritakan Negara Maespati dilanda kekeringan dan Prabu Harjunasasra akan membendung pantai Parangtritis agar airnya meluap ke daratan dan para rakyat Maespati tidak kesusahan mencari air. Harjunasasrabahu berhasil membendung pantai dengan bertiwikrama menjadi rasaksa besar lalu tidur di laut. Air laut meluap ke daratan yang mengalami kekeringan, namun air laut yang meluap juga membanjiri pakuwon Dasamuka. Dasamuka marah dan menyerang Harjunasasra. Patih Suwanda berhasil menghalangi Dasamuka, akan tetapi Suwanda kalah, mati digigit oleh Dasamuka. Prabu Dasamuka setelah membunuh Patih Suwanda mencari Harjunasasra. Terjadi peperangan antara Prabu Harjunasasra yang berwujud rasaksa melawan Dasamuka. Dasamuka disiksa dengan diinjak-injak dan diseret dengan kereta di sepanjang jalan Maespati.

Lakon Bedhah Maèspati karya Ki Margiono (2016) menceritakan Prabu Dasamuka diutus Prabu Harjunasasrabahu untuk membantu mencari buron wana. Prabu Dasamuka merasa diremehkan oleh Prabu Harjunasasrabahu, akan tetapi Prabu Dasamuka menyanggupinya dan memikirkan cara mengalahkan Prabu Harjunasasrabahu. Setelah mendapat bujukan Kala Marica, Prabu Dasamuka memerintahkan prajurit Ngalengka menyamar menjadi prajurit Maespati untuk menindas rakyat Maespati. Prajurit Ngalengka pun mendatangi Begawan Jamadagni untuk menagih upeti dengan cara memaksa. Merasa ayahnya diperlakukan tidak sopan dan kasar oleh prajurit Maespati, Rumawan dan Susena melawan prajurit Maespati. Prajurit Maespati kalah. Begawan Jamadagni menghadap Prabu Harjunasasrabahu mengadukan para prajurit Maespati yang menagih upeti dengan kasar dan semena-mena. Prabu Dasamuka bertemu dengan Ramabargawa. Prabu Dasamuka menceritakan bahwa dirinya diutus Prabu Harjunasasrabahu untuk mencari buron wana. Prabu Dasamuka juga menceritakan kepada Ramabargawa jika Prabu Harjunasasrabahu telah semena-mena terhadap rakyat saat menagih upeti. Hal ini membuat Ramabargawa marah karena 
raja Maespati telah bertindak sewenang-wenang terhadap rakyat. Prabu Harjunasasrabahu bertemu Begawan Jamadagni. Sang begawan menceritakan keluh kesah rakyat Maespati. Merasa tersinggung, Prabu Harjunasasrabahu marah dan melemparkan senjata Cakra ke arah Begawan Jamadagni sehingga mati. Ramabargawa yang melihat dari kejahuan ayahnya terbunuh semakin marah terhadap Harjunasasrabahu. Prabu Harjunasasrabahu terkena kampak Bargawastra milik Ramabargawa akhirnya tewas.

Lakon Banjaran Ramabargawa karya Ki Hadi Sutikno (2009) menceritakan perjalanan hidup Ramabargawa mencari titisan Wisnu. Ramabargawa bersumpah akan membunuh orang-orang Maespati yang telah menyebabkan kehidupan rumah tangga ayah dan ibunya rusak. Dalam perjalanan, Ramabargawa bertemu dengan Prabu Harjunasasrabahu. Ramabargawa menantang Prabu Harjunasasrabahu karena ia menganggap Prabu Harjunasasrabahu titisan Wisnu. Prabu Harjunasasrabahu tewas terkena kampak Bargawastra milik Ramabargawa. Setelah kematian Prabu Harjunasasrabahu, Negara Maespati pun binasa terkena gempa. Dewi Citrawati beserta seluruh rakyat dan prajurit tewas tanpa sisa hingga lenyaplah kerajaan Maespati.

Cerita tentang Maespati sudah ditulis oleh para penulis dan para dalang. Diantaranya balungan lakon Sumantri Ngèngèr dalam Serat Kandhaning Ringgit Purwa karya K.G.P.A.A Mangkunegara VII (1965); Serat Harjuna Sasrabahu karya R.Ng Sindusastra jilid IV bagian VII (1932); Novel epic Arjuna Sasrabahu karya Sunardi D.M (1982), Nonton Wayang dari Berbagai Pakeliran karya R.M Pranoedjoe Poesponingrat (2008) dan Balungan Lakon versi mBah Jayeng Taryono karya Ki Suparman Cerma Wiyata (1985), balungan lakon Harjunasasrabahu Léna karya Ki Cerma Sutejo (2016), balungan lakon Rubuhipun Harjunasasrabahu karya Ki Sugati (2016).

K.G.P.A.A Mangkunegara VII (1965) menulis cerita tentang Maespati dalam balungan lakon Sumantri Ngèngèr. Dalam balungan lakon ini diceritakan bahwa Sumantri berhasil memboyong Dewi Citrawati ke Maespati. Sebelum menyerahkan Dewi Citrawati Sumantri ingin mencoba kesaktian Prabu Harjunasasrabahu karena Sumantri ingin mengabdikan dirinya kepada orang yang lebih sakti dari dirinya. Sumantri kalah melawan Prabu Harjunasasrabahu. Sebagai hukuman karena melawan raja, Sumantri diperintahkan Prabu Harjunasasrabahu memindahkan Taman Sri Wedari ke Maespati dari Kahyangan Untara Segara. Merasa kesulitan, Sumantri meminta tolong adiknya yaitu Sukrasana. Dengan bantuan Sukrasana, Taman Sri Wedari dapat dipindah ke Maespati.

R.Ng Sindusastra jilid IV bagian VII (1932) menulis cerita tentang Maespati dalam bentuk tembang. Diceritakan bahwa Prabu Harjunasasra mendapat petunjuk dari Bethara Narada jika Dewi Sri telah menitis di tubuh putri Magada yang bernama Dewi Citrawati. Prabu Harjunasasrabahu saat di pasewakan bertanya kepada para raja yang hadir tentang Dewi Citrawati. Raja Soda menceritakan bahwa Dewi Citrawati adalah putri raja Magada putri Prabu Citradarma. Prabu Citradarma telah wafat dan digantikan oleh putra bungsunya Prabu Citradarma adik Dewi Citrawati. Kerajan Magada saat ini dalam cengkraman raja Widarba, karena lamarannya ditolak oleh Dewi Citrawati. Prabu Harjunasasrabahu akan membantu negara Magada dan melamar Dewi Citrawati.

Novel epic Arjuna Sasrabahu karya Sunardi D.M(1982) episodeSumantri Ngenger menceritakan bahwa Sumantri berhasil mengalahkan Prabu Darmawasesa dan memboyong Dewi Citrawati. Sesampainya di Maespati, Dewi Citrawati kemudian meminta Prabu Harjunasasrabahu untuk memindahkan Taman Sri Wedari ke Maespati. Prabu Harjunasasrabahu memerintahkan Sumantri untuk memindahkan Taman Sri Wedari ke Maespati. Berkat pertolongan adiknya Sukrasana, Sumantri berhasil memindahkan Taman Sri Wedari.

R.M Pranoedjoe Poespaningrat (2008) menuliskan cerita kehancuran Negara Maespati dimulai dari gugurnya Patih Suwanda. Dalam buku ini diceritakan bahwa Harjunasasrabahu adalah raja yang kurang bijaksana karena selalu memenuhi permitaan Dewi Citrawati dan menganiaya Dasamuka kelewat batas dengan cara diseret di belakang kereta. Dewi Citrawati menginginkan dibuatkan pemandian di Sungai Narmada. Demi menuruti permintaan Dewi Citrawati, Prabu Harjunasasrabahu bertiwikrama dan merebahkan diri untuk membendung Sungai 
Narmada. Akibatnya air Sungai Narmada meluap dan membanjiri perkemahan Prabu Dasamuka. Prabu Dasamuka marah dan terjadilah perang antara Dasamuka dengan Prabu Harjunasasrabahu. Prabu Dasamuka kalah dan diseret di Negara Maespati. Prabu Sumali tidak tega melihat cucunya, Prabu Dasamuka diperlakukan seperti itu. Ia lalu memohonkan ampun pada Prabu Harjunasasrabahu. Prabu Harjunasasrabahu memberikan ampun tetapi Dasamuka harus tunduk pada Prabu Harjunasasrabahu dan semua yang mati dapat dihidupkan. Semua dapat hidup kembali kecuali Patih Suwanda. Setelah patihnya gugur, Prabu Harjunasasrabahu menjadi kurang bijaksana dan Wisnu oncat. Prabu Harjunasasrabahu membunuh Begawan Jamadagni beserta keluarganya kecuali Bargawa karena sedang ada di hutan. Bargawa marah dan akan menghabisi Prabu Harjunasasrabahu. Prabu Harjunasasrabahu tewas dan kerajaan Maespati runtuh.

Ki Suparman Cerma Wiyata (1985) menuliskan lakon Bedhahipun Maèspati dalam bentuk Balungan Lakon versi mbah Jayeng Taryono. Dalam lakon ini diceritakan Prabu Harjunasasrabahu akan mengadakan pesta dan mengutus Dasamuka untuk mencarikan buron wana. Di Kedhaton Maespati terjadi keributan karena ada penyusup yaitu Prabu Garbawasesa. Prabu Harjunasasrabahu mengejar penyusup di Kedhaton Maespati. Terjadilah peperangan antara Prabu Garbawasesa dan Prabu Harjunasasrabahu. Hal ini dimanfaatkan Dasamuka untuk menipu Dewi Citrawati. Dasamuka memerintahkan Sukrasana, menyamar menjadi Emban untuk menipu Dewi Citrawati. Citrawati mendapat laporan dari Emban bahwa Harjunasasrabahu mati menghadapi Prabu Garbawasesa. Dewi Citrawati mendengar kabar itu lalu bunuh diri. Dewi Widowati yang semula bersemayam dalam tubuh Dewi Citrawati oncat. Prabu Garbawasesa akhirnya mati di tangan Prabu Harjunasasrabahu. Melihat Prabu Garbawasesa tewas, Ramabargawa segera melepaskan panah Garbawastra dan tewaslah Prabu Harjunasasrabahu. Dasamuka memerintahkan Sukrasana untuk pergi ke Sonyapringga melaporkan berita bohong. Resi Subali mendapat kabar jika Dewi Tara dihajar oleh Sugriwa. Resi Subali marah dan menghajar Sugriwa. Raja Sengkala, sekutu Prabu Harjunasasrabahu mendapat kabar jika Prabu Harjunasasrabahu telah mati. Raja Sengkala mengira bahwa ini semua karena ulah Dasamuka. Ia segera menghadapi Dasamuka. Raja Sengkala, prajuritnya, dan prajurit Maespati kalah dan tewas.

Ki Cerma Sutejo (2016) menulis cerita kehancuran Maespati dengan judul lakon Harjunasasrabahu Léna. Dalam sanggit lakon Ki Cerma Sutejo, Prabu Dasamuka tidak terima karena Negara Ngalengka menjadi raja taklukan Negara Maespati. Dasamuka mendapat undangan dari Prabu Harjunasasrabahu untuk pesta di Maespati. Dasamuka menghadiri undangan tersebut dan berniat untuk membunuh Prabu Harjunasasrabahu. Prabu Sasrakumala pergi ke Maespati menculik Dewi Citrawati untuk dijadikan istri setelah mendapat wangsit bahwa Batara Wisnu akan oncat dari diri Harjunasasrabahu. Di Kahyangan Jongringsaloka, Batara Guru memerintahkan Batara Yamadipati untuk membanjud Harjunasasrabahu.

Negara Maespati diserang musuh dari Negara Simbarkencana yang dipimpin oleh Prabu Sasrakumala. Prabu Sasrakumala berhasil membawa pergi Dewi Citrawati. Prabu Harjunasasrabahu bingung menghadapi Sasrasengkala. Begawan Suryasengkala, Trikala, dan Kalasekti datang ke Maespati guna mencari ayahnya yaitu Prabu Harjunasasrabahu. Prabu Harjunasasrabahu bersedia mengakui Trikala dan Kalasekti sebagai putranya jika mampu mengalahkan Prabu Sasrakumala. Trikala dan Kalasekti pergi mencari Prabu Sasrakumala dibantu Begawan Suryasengkala. Prabu Sasrasengkala akhirnya mati sampyuh dengan Begawan Suryasengkala. Melihat kematian Sasrakumala, Ramabargawa marah dan segera melepaskan kampak Bargawastra ke arah Prabu Harjunasasrabahu hingga tewas. Melihat Harjunasasrabahu tewas, Dewi Citrwati bunuh diri. Dewi Widowati yang semula menitis di raga Dewi Citrawati oncat. Dasamuka mengejar Dewi Widowati. Trikala dan Kalasekti diboyong Prahasta ke Ngalengka untuk dijadikan putra angkatnya.

Dalam sanggit balungan lakon Rubuhipun Harjunasasrabahu versi Ki Sugati (2016), diceritakan Prabu Harjunasasrabahu mencari buron wana atas permintaan Dewi Citrawati. Di dalam hutan, Prabu Harjunasasrabahu bertemu Begawan Jamadagni. Begawan Jamadagni dihasut oleh Dasamuka yang menyamar menjadi rakyat Maespati dengan mengatakan bahwa Prabu Harjunasasrabahu 
telah sewenang-wenang dan menindas rakyat. Hal ini membuat Begawan Jamadagni marah dan menantang Prabu Harjunasasrabahu. Prabu Harjunasrabahu marah dan melepaskan senjata Cakra ke arah Begawan Jamadagni. Ramabargawa marah karena ayahnya dibunuh oleh Prabu Harjunasasrabahu. Ramabargawa berperang melawan Prabu Harjunasasrabahu. Dalam pertempuran, Prabu Harjunasasrabahu dapat dikalahkan oleh Ramabargawa karena Prabu Harjunasasrabahu bukan titisan Batara Wisnu lagi. Ramabargawa menghancurkan Negara Maespati dengan kampak Bargawastra. Para prajurit dan punggawa Maespati mati di tangan Ramabargawa. Dewi Citrawati lari dikejar oleh Dasamuka. Dewi Citrawati yang sedang hamil dibunuh oleh Dasamuka dengan cara menyobek perut dan mengelurkan bayi yang ada dalam perut Dewi Citrawati. Bayi dibuang dan ditemu oleh Patih Prahasta lalu dijadikan anak angkat. Setelah Dewi Citrawati mati, Dewi Widowati oncat dari tubuh Dewi Citrawati. Melihat Dewi Widowati oncat Dasamuka segera mengejarnya.

\section{Konsep Sanggit}

Kisah-kisah Harjunasasrabahu terutama tentang kematiannya atau kehancuran Negara Maespati seperti telah dipaparkan di depan, dalam karya ini akan diinterpretasi ulang atau dalam istilah pedalangan disebut disanggit.

Konsep sanggit seperti dikemukakan oleh Soetarno dkk. (2007) dipakai sebagai kerangka pikir dalam menggarap lakon Brubuh Maèspati. Soetarno dkk. (2007) mengatakan bahwa sanggit berasal dari kata gesangé anggit yang berarti kreativitas dalang yang berhubungan dengan penafsiran dan penggarapan unsur-unsur pakeliran untuk mencapai kemantapan estetik pertunjukan wayang (Feinstein dkk., 1986: xxxiv, Murtiyoso, 1979/1980: 12 via Soetarno dkk., 2007: 54). Selanjutnya Soetarno dkk. (2007:54) menyatakan bahwa sanggit dalam pedalangan dapat disamakan dengan garap. Sanggit sebagai wahana pembawa pesan dan penggarapan unsur pakeliran meliputi garap lakon, garap adegan, garap tokoh, garap catur, garap sabet, dan garap iringan karawitan (Subono, 1996:15-18, Murtiyoso, 1979/1980: 12 via Soetarno dkk., 2007: 54). Soetarno dkk.
(2007: 54) juga mengatakan bahwa sanggit bertujuan memberikan peluang dan ruang bagi dalang memunculkan kecenderungan pribadi dalam pertunjukan wayang. Secara singkat konsep sanggit dapat dilihat dalam gambar 1 .

Berdasarkan konsep tersebut, Brubuh Maèspati yang merupakan sanggit dari pengkarya akan diwujudkan. Penggarapan Brubuh Maèspati dimulai dengan menonton dan membaca lakonlakon yang berhubungan dengan kerajaan Maespati. Ada tiga lakon yang dipilih menjadi landasan dalam menafsir nilai kesetiaan yaitu lakon Sumantri Ngèngèr, Dasamuka Gladhak, dan Brubuh Maèspati. Selanjutnya dilakukan garap lakon, garap tokoh, garap adegan, dan garap iringan karawitan sesuai dengan estetika pakeliran Yogyakarta. Gambar 2 menunjukkan bagaimana konsep sanggit diterapkan dalam sanggit lakon Brubuh Maèspati.

\section{Penafsiran (Interpretasi Ulang) atas Nilai Kesetiaan}

Beberapa lakon yang mengisahkan Harjunasasrabahu, Dewi Citrawati, Suwanda, dan Dasamuka seperti dikemukakan di depan setelah dicermati ditemukan banyak hal yang menarik untuk ditanyakan. Pertama, mengapa Harjunasasrabahu tidak melamar sendiri Dewi Citrawati yang sangat dicintainya? Oleh karena itu pengkarya ingin menjawab pertanyaan ini. Dalam karya Brubuh Maèspati ini akan

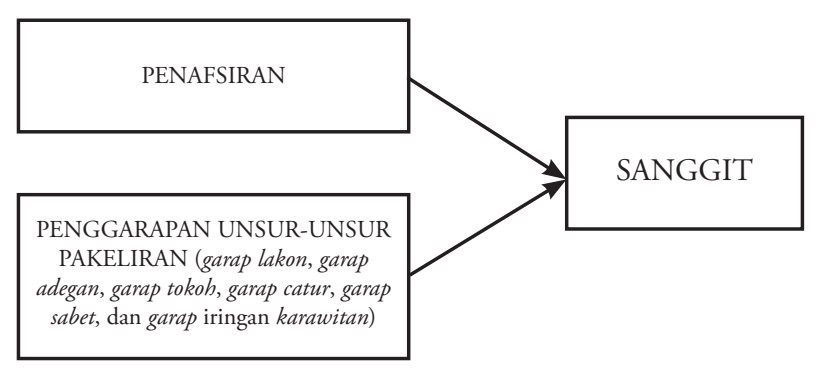

Gambar 1. Skema konsep sanggit.

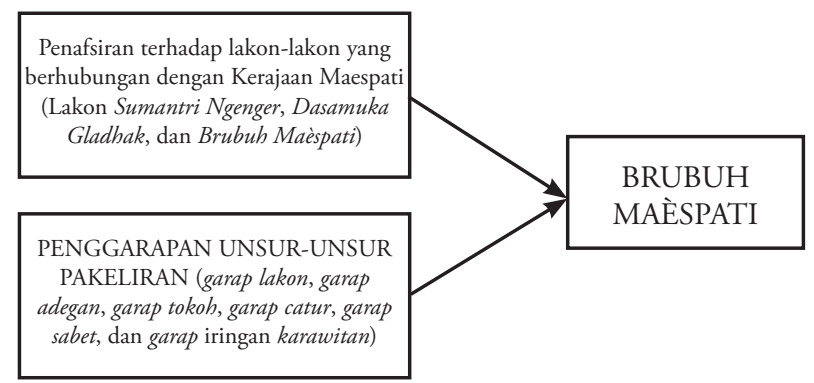

Gambar 2. Skema sanggit Brubuh Maèspati. 
ditampilkan Prabu Harjunasasrabahu melamar sendiri Dewi Citrawati. Hal ini dilakukan karena ingin menunjukan kejantanan dan bukti awal cinta Prabu Harjunasasrabahu kepada Dewi Citrawati.

Kedua, Dasamuka setelah dikalahkan Harjunasasrabahu rupa-rupanya ditafsir oleh banyak dalang memiliki dendam terhadap peristiwa itu. Maka lahirlah lakon Bedhah Maèspati atau Harjunasasrabahu Léna yang menceritakan kelicikan-kelicikan Dasamuka dalam merongrong kekuasaan dan menghancurkan kerajaan Maespati. Kelicikan Prabu Dasamuka akan dijadikan pijakan dalam penggarapan Brubuh Maèspati, terutama digunakan untuk membangun konflik dan akhir perjalanan hidup tokoh Harjunasasrabahu.

Ketiga, dari lakon-lakon yang berhasil dicermati kiranya dapat ditarik sebuah asumsi bahwa kehancuran Maespati disebabkan oleh permintaan Dewi Citrawati kepada Harjunasasrabahu. Artinya dalam banyak lakon tersebut nilai kesetiaan (Harjunasasrabahu) disampaikan. Dalam Lakon Brubuh Maèspati ini, pengkarya ingin menyampaikan tafsir ulang atau interpretasi atas nilai kesetiaan baik sebagai pribadi maupun sebagai warga masyarakat. Interpretasi ulang atas nilai kesetiaan ini akan dituangkan dalam pertunjukan wayang kulit purwa tradisi inovatif yang berdurasi kurang lebih dua setengah jam.

\section{Balungan Lakon Brubub Maèspati}

Lakon Brubuh Maèspati ini menceritakan kisah cinta tokoh Harjunasasrabahu dengan Citrawati yang menimbulkan kehancuran kerajaan Maespati karena terlalu memanjakan Citrawati dan terlalu mencintai Citrawati. Adapun sanggit lakon Brubuh Maèspati sebagai berikut.

\section{Pathet Nem}

\section{Jejer I Negara Maespati}

Prabu Harjunasasrabahu tengah mengadakan persidangan di sitinggil Negara Maespati dengan dihadiri Patih Suwanda dan Tumenggung Surata. Paséwakan dihadirkan dalam suasana agung. Secara umum pagelaran wayang kulit tradisi Yogyayakarta menggunakan iringan Ayak-ayak Lasem slendro pathet nem kemudian masuk ke Gendhing Karawitan dan diakhiri Ladrang Karawitan. Akan tetapi mengingat durasi waktu yang singkat, pengkarya akan menggunakan Ayak-ayak slendro nem dan Gendhing Karawitan hanya sampai pada kenong dua diteruskan ke Ladrang Peksi Kuwung. Dalam tradisi pedalangan Yogyakarta selesai janturan dilanjutkan Suluk Lagon slendro pathet nem wetah dan Ada-Ada Kawin Sikarini atau Kawin Girisa, tetapi pengkarya akan menyajikan Suluk Lagon Nem Wetah dengan cara diputus pada bagian syair lir kilat sisiring thatit. Hal ini dikarenakan pengkarya menyajikan pakeliran padat dan pemotongan syair berdasarkan pathet gending yang digunakan pengkarya pathet nem bernada gong lima.

Dalam jejer pertama Prabu Harjunasasrabahu membahas keinginan untuk menyelamatkan Negara Magada dari cengkraman Prabu Darmawasesa. Prabu Harjunasasrabahu digambarkan sudah saling kenal dengan Dewi Citrawati dan selalu menjalin komunikasi dengan Dewi Citrawati. Oleh karena itu Prabu Harjunasasrabahu dimintai tolong Dewi Citrawati untuk mengusir Prabu Darmawasesa dari Negara Magada. Prabu Harjunasasrabahu akan berangkat sendiri ke Magada melawan Prabu Darmawasesa namun dilarang oleh Patih Suwanda. Suwanda mengkhawatirkan keselamatan rajanya. Patih Suwanda bersedia menjadi duta penglamar dan membebaskan Negara Magada dari cengkraman Prabu Darmawasesa. Prabu Harjunasasrabahu menolak usulan Patih Suwanda karena Prabu Harjunasasrabahu ingin menunjukan kejantanannya kepada Dewi Citrawati. Patih Suwanda dan para prajurit akan mengikuti Prabu Harjunasasrabahu. Prabu Harjunasasrabahu hanya memperbolehkan Patih Suwanda beserta prajurit melawan wadyabala Widarba. Prabu Harjunasasrabahu berganti busana kerajaan menjadi busana peperangan. Iringan yang digunakan adalah Playon Lasem slendro pathet nem. Sesampainya di luar sitinggil, Patih Suwanda melihat dhampar kencana (singgasana) terbakar, Patih Suwanda terkejut. Keterkejutan Patih Suwanda didukung iringan

\footnotetext{
1 Berdasarkan wawancara dengan Ki Cerma Sutejo di kediamanya Gedong Kuning, Banguntapan, Bantul, Yogyakarta, 20 November 2017.
} 
Playon Lasem bertempo seseg. Setelah iringan Playon Lasem di-suwuk, Patih Suwanda mengungkapkan rasa kebingungan dengan bertanya kepada Tumenggung Surata siapakah Dewi Citrawati dan bagaimana wataknya. Tumenggung Surata menjelaskan bahwa Dewi Citrawati adalah anak Prabu Citradarma, kakak Prabu Citragada. Dewi Citrawati adalah putri yang manja dan mudah tersinggung. Patih Suwanda berpendapat, kekurangan Dewi Citrawati bisa meruntuhkan kerajaan Maespati. Suwanda dan Surata berangkat mengikuti Prabu Harjunasasra. Surata memerintahkan para prajurit untuk budhal ke Magada. Para prajurit berangkat ke Negara Magada dengan diiringi Lancaran Simo Nebak.

\section{Adegan Negara Magada}

Prabu Harjunasasabahu dan Prabu Citragada bertemu. Prabu Citragada bergembira karena Prabu Harjunasasrabahu datang menyelamatkan negaranya yang dijajah oleh Darmawasesa. Kegembiraan Prabu Citragada didukung dengan pergantian iringan Lancaran Sima Nebak menjadi Playon Lasem. Prabu Citragada mengantarkan Prabu Harjunasasrabahu bertemu dengan Prabu Darmawasesa. Prabu Harjunasasra berperang dengan Prabu Darmawasesa. Prabu Darmawasesa kalah kemudian pergi dari Negara Magada.

\section{Jejer II Taman Sari Negara Magada}

Dewi Citrawati sedang duduk di taman. Secara tradisi pedalangan Yogyakarta, untuk menandakan alur lakon memasuki jejer II dalang melantunkan Suluk Lagon Plencung Wetah slendro pathet nem (Mudjanattitomo, 1977: 101). Mengingat durasi waktu yang pendek pengkarya tidak menggunakan Suluk Lagon Plencung Wetah, tetapi melangsungkan perpindahan iringan Playon Lasem masuk ke Ketawang Sarawasti slendro pathet manyura.

Prabu Citragada datang menemui Dewi Citrawati. Prabu Citragada bertanya kepada Dewi Citrawati tentang lamaran Prabu Harjunasasra diterima ataukah ditolak. Dewi Citrawati mengatakan bahwa dirinya menerima lamaran Prabu Harjunasasrabahu. Prabu Citragada keluar taman kemudian memanggil Prabu Harjunasasra untuk masuk ke taman. Prabu Harjunasasrabahu bertemu Dewi
Citrawati di taman membicarakan tentang hubungannya. Pertemuan Prabu Harjunasasrabahu dan Dewi Citrawati terjadi dalam suasana tenang dengan lantunan Suluk Lagon Plencung Jugag. Dewi Citrawati dan Prabu Harjunasasrabahu kemudian menikah di Negara Magada. Pernikahan Prabu Harjunasasrabahu dan Dewi Citrawati berlangsung dengan suasana megah dan agung. Suasana tersebut digambarkan dengan iringan Kodhok Ngorèk.

\section{Adegan Kedhaton Negara Magada}

Dewi Citrawati meminta kepada Prabu Harjunasasrabahu berbagai macam, mulai dari busana, pengawal, dan turunnya Taman Sri Wedari. Suasana dalam adegan kedhaton Negara Magada penuh dengan kegembiran dan menggambarkan kesuburan. Hal ini diwujudkan oleh pengkarya dengan Ketawang Tarupala, masuk ke Ketawang garap dan diakhiri dengan Kemuda garap. Prabu Harjunasasrabahu menuruti semua keinginan Dewi Citrawati. Untuk menggambarkan turunnya Taman Sri Wedari yang megah dan indah, pengkarya menggambarkan dengan iringan lancaran garap dengan tempo irama II. Taman Sri Wedari diturunkan ke Magada, semua orang tertarik akan keindahan Taman Sri Wedari. Untuk membangun suasana tegang pengkarya menambah adegan keributan yaitu Patih Suwanda mencoba ingin masuk ke Taman Sri Wedari tetapi dihalangi oleh pengawal Dewi Citrawati. Terjadilah pertarungan antara pengawal Dewi Citrawati dengan Patih Suwanda. Prabu Harjunasasrabahu berhasil memisah Patih Suwanda. Patih Suwanda menyarankan Prabu Harjunasasrabahu pulang ke Maespati karena Maespati sudah lama ditinggalkan. Taman Sri Wedari dipindah oleh Prabu Harjunasasrabahu ke Maespati. Perpindahan dan kepulangan Prabu Harjunasasrabahu ke Maespati ini digambarkan dengan iringan Playon Madya Ratri yang berasa Pathet Sanga. Hal ini digunakan pengkarya untuk memindah Pathet Nem ke Pathet Sanga pada Jejer III Kedhaton Maespati.

\section{Jejer III Kedhaton Maespati}

Prabu Harjunasasrabahu bertanya kepada Dewi Citrawati, mengapa sejak tinggal di Maespati Dewi Citrawati terlihat berbeda. Dewi Citrawati meminta kepada Prabu Harjuna- 
sasrabahu untuk membendung Sungai Narmada karena ia ingin mandi di Sungai Narmada. Prabu Harjunasasrabahu menyanggupinya. Patih Suwanda datang menemui Dewi Citrawati.

Dalam tradisi Pedalangan Yogyakarta perpindahan Pathet Nem ke Pathet Sanga ditandai Suluk Lagon Sanga Wetah. Akan tetapi dalam karya ini pengkarya menggunakan SulukAda-ada Sanga Jugag, hal ini dikarenakan pengkarya ingin mengangkat suasana karena terjadinya konflik antara Patih Suwanda dan Dewi Citrawati. Patih Suwanda meminta Dewi Citrawati agar berhenti mengajukan banyak permintaan kepada Prabu Harjunasasrabahu. Permintaan itu membuat Prabu Harjunasasrabahu lupa akan kewajibanya sebagai raja. Patih Suwanda juga meminta agar permintaan Dewi Citrawati mandi di Sungai Narmada ditunda dulu. Karena hal ini membahayakan para rakyat Maespati yang tinggal di tepi sungai. Terjadilah perselisihan pendapat. Merasa tersinggung Patih Suwanda pergi. Kepergian Patih Suwanda mengakhiri konflik dan perselisihan pendapat serta perpindahan Pathet Nem ke Pathet Sanga.

\section{Pathet Sanga}

\section{Adegan Tepi Sungai Narmada}

Prabu Harjunasasrabahu bertiwikrama menjadi rasaksa besar. Ia tidur di tengah Sungai Narmada dengan posisi melintang. Air sungai yang terbendung pun meluap. Untuk membangun konflik, pengkarya menggambarkan meluapnya air Sungai Narmada membanjiri pakuwon Dasamuka. Pengkarya juga membangun suasana tegang dengan iringan Playon Sanga berirama seseg. Untuk menggambarkan kemarahan Prabu Dasamuka dan keagungannya pengkarya menggambarkan dengan iringan Ladrang Kagog Medura saat Prabu Dasamuka keluar. Prabu Dasamuka melihat Prabu Harjunasasrabahu bertiwikrama menjadi rasaksa membendung Sungai Narmada.

\section{Jejer IV Tepi Sungai Narmada}

Patih Suwanda dihadap para Punakawan. Dalam pakeliran tradisi Yogyakarta keluarnya Punakawan pada umumnya pada adegan garagara. Tetapi mengingat durasi waktu yang pendek, pengkarya tidak menampilkan adegan gara-gara, melainkan dengan adegan jejer $I V$ atau séba. Keluarnya tokoh Punakawan Semar bersamaan dengan Patih Suwanda diiringi lantunan Suluk Jingking sléndro pathet sanga. Patih Suwanda mengutarakan isi hatinya, ia bingung karena Prabu Harjunasasrabahu selau menuruti permintaan istrinya, Dewi Citrawati. Tak lama kemudian Prabu Dasamuka datang untuk mencari Prabu Harjunasasrabahu dan merebut Negara Maespati. Terjadilah peperangan antara Dasamuka dan Suwanda. Patih Suwanda mati digigit oleh Prabu Dasamuka. Untuk membangun suasana sedih pengkarya mengunakan iringan Playon Tlutur slendro pathet sanga.

\section{Pathet Manyura}

Semar melaporkan kepada Prabu Harjunasasrabahu bahwa Prabu Dasamuka mengamuk dan Patih Suwanda mati digigit Prabu Dasamuka. Prabu Harjunasasrabahu kemudian melawan Prabu Dasamuka. Dalam tradisi pedalangan perpindahan Pathet Sanga ke Pathet Manyura menggunakan Suluk Lagon Manyura Wetah, tetapi pengkarya akan menggunakan Kombangan nada lu (dhadha). Hal ini digunakan pengkarya untuk menghemat waktu dan suasana tegang tidak turun.

Prabu Dasamuka kalah dan disiksa oleh Prabu Harjunasasrabahu dengan cara diinjak-injak. Pada karya tulis atau karya-karya yang lain Prabu Dasamuka diseret oleh Prabu Harjunasasrabahu menggunakan kereta dan menghadirkan Resi Pulasta untuk memohonkan ampun kepada Prabu Harjunasarabahu. Hal ini tidak pengkarya tampilkan karena mengingat durasi waktu dan tidak ada turunnya suasana tegang. Prabu Dasamuka menyerah, dan Prabu Harjunasasrabahu melepaskan Prabu Dasamuka. Prabu Dasamuka kemudian berubah wujud menjadi rakyat Maespati guna mengadu domba Begawan Jamadagni dan Prabu Harjunasasra.

\section{Adegan Tepi Sungai Narmada}

Untuk menimbulkan konflik di akhir cerita pengkarya menyanggit Prabu Dasamuka yang menyamar menjadi rakyat jelata menemui Begawan Jamadagni. Prabu Dasamuka mengadu domba Begawan Jamadagni dengan Prabu Harjunasasrabahu. Begawan Jamadagni terhasut oleh omongan Dasamuka kemudian pergi mencari Prabu Harjunasasrabahu. 
Begawan Jamadagni bertemu dengan Prabu Harjunasasrabahu. Begawan Jamadagni marahmarah kepada Prabu Harjunasasrabahu karena Prabu Harjunasasrabahu membendung Sungai Narmada dan selalu menuruti permintaan Dewi Citrawati hingga lupa akan kewajibannya sebagai raja. Prabu Harjunasasrabahu merasa tersinggung kemudian marah, mengeluarkan senjata Cakra Baskara ke arah Begawan Jamadagni. Begawan Jamadagni mati terkena senjata Cakra. Batara Wisnu oncat. Ramabargawa menemui Prabu Harjunasasrabahu. Ramabargawa berperang melawan Prabu Harjunasasrabahu. Prabu Harjunasasra mati terkena kampak Bargawastra. Agar suasana menjadi tegang, pengkarya menambahkan iringan ilustrasi. Batara Wisnu Murti bertemu dengan Batara Basuki yang keluar dari tubuh Ramabargawa. Keluarnya kedua dewa ini bersamaan dengan perpindahan iringan ilustrasi berubah ke Ketawang Mijil Dhempel. Hal ini digunakan pengkarya agar suasana tegang berubah menjadi agung dan penuh dengan pituah. Batara Wisnu Murti menjelaskan bahwa tugasnya menitis di raga Harjunasasrabahu telah selesai dan Negara Maespati akan hancur berubah menjadi hutan belantara. Batara Wisnu Murti menitipkan Negara Maespati kepada Batara Basuki kemudian pergi meninggalkan Prabu Harjunasasrabahu. Batara Basuki kembali ke tubuh Ramabargawa. Ramabargawa bertemu dengan prajurit Ngalengka yang akan mengambil kayu-kayu di hutan Maespati. Ramabargawa berperang melawan prajurit Ngalengka. Para Prajurit Ngalengka kalah kemudian mundur. Dalam adegan akhir pengkarya menampilkan tokoh Punakawan sebelum tanceb kayon.

\section{Pemilihan Boneka Wayang}

Penokohan dalam sebuah pertunjukan wayang adalah penyampaian gagasan pokok dan tema dalam cerita. Di samping itu penokohan juga merupakan proses penampilan tokoh sebagai pembawa peran watak dalam suatu pementasan lakon (Satoto, 1985:24). Agar gagasan pokok dan tema cerita dapat disampaikan maka haruslah ditentukan karakter dari tokoh yang akan ditampilkan. Karakter dari setiap tokoh tersebut yang nantinya akan menentukan alur dan membentuk kualitas tindakan (Wahyudi, 2011: 59).

Berpijak dari pemikiran tersebut, keberadaan tokoh sangat penting dalam penyusunan alur cerita yang akan dikisahkan, sehingga penentuan tokoh-tokoh yang terlibat perlu diperhatikan karakterisasinya. Adapun tokoh-tokoh yang dipilih dalam karya lakon Brubuh Maèspati adalah sebagai berikut.

a. Prabu Harjunasasrabahu

Harjunasasrabahu adalah raja Negara Maespati. Dalam karya ini dikisahkan Prabu Harjunasasrabahu sangat mencintai istrinya dan selalu menuruti permintaan Dewi Citrawati. Pemilihan boneka wayang Harjunasasrabahu berdasarkan wawancara dengan dalang senior Yogyakarta, Ki Cerma Sutejo. Bentuk wayang Prabu Harjunasasrabahu seperti Prabu Ramawijaya tetapi memakai rambut, tidak memakai sampir dan jangkahan seperti Prabu Watu Gunung. Pengkarya membuat dua tokoh Harjunasasrabahu dengan wujud bokongan dan jangkahan. Saat paséwakan atau jejer digunakan boneka wayang bokongan, dan saat keluar istana digunakan boneka wayang jangkahan. Adapun bentuk ciri-cirinya sebagai berikut. Muka luruh gembleng, mata gabahan, mulut salitan memakai mahkota raja, memakai praba serta kelat bahu ngangrangan dan ulur-ulur naga mamangsa. Bentuk wayang Prabu Harjunasasrabahu dapat dilihat pada gambar 3 dan 4 .

b. Dewi Citrawati

Citrawati adalah putri Negara Magada, kakak Prabu Citragada. Dalam lakon Brubuh Maèspati ini dikisahkan Dewi Citrawati adalah

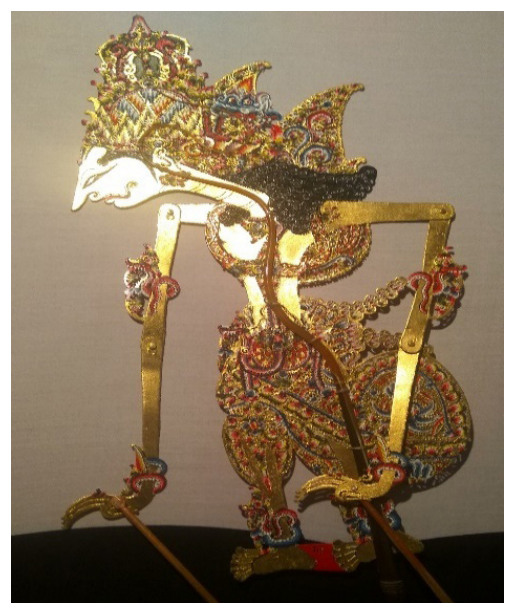

Gambar 3. Prabu Hajunasasrabahu bokongan koleksi Joko Laras Moyo. (Foto: Joko Laras Moyo, 2018) 
istri Prabu Harjanuasasrabahu yang sangat manja dan memiliki banyak permintaan.

Pemilihan boneka wayang Dewi Citrawati pada karya ini berdasarkan hasil wawancara dengan dalang Ki Cerma Sutejo. Sejauh pengamatan pengkarya belum ditemukan wayang baku untuk tokoh Dewi Citrawati, maka pengkarya akan meminjam tokoh putrèn srambahan. Adapun bentuk dan ciri-cirinya sebagai berikut: putrèn dengan muka luruh, mata gabahan, memakai mahkota pogog, mulut salitan, dan kelat bahu naga pangangrang. Boneka wayang Dewi Citrawati dapat dilihat pada gambar 5 .

c. Prabu Citragada

Prabu Citragada Raja Magada, adik Dewi Citrawati, putra Prabu Citradarma. Dalam lakon Brubuh Maespati ini dikisahkan Prabu Citragada adalah adik Dewi Citrawati yang telah menggantikan ayahnya menjadi raja di Negara Magada.

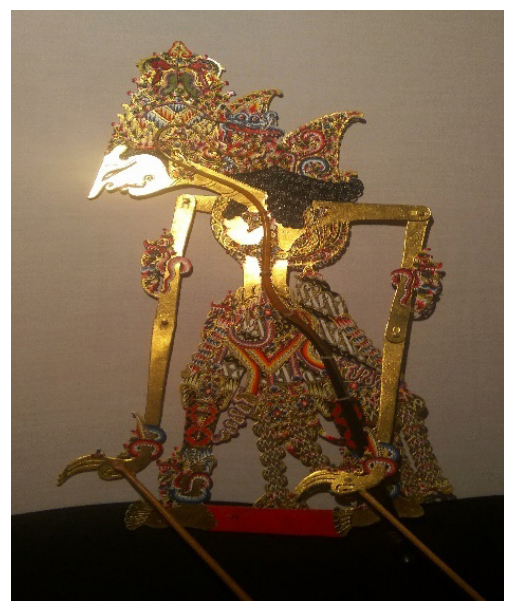

Gambar 4. Prabu Hajunasasrabahu jangkahan koleksi Joko Laras Moyo. (Foto: Joko Laras Moyo, 2018)

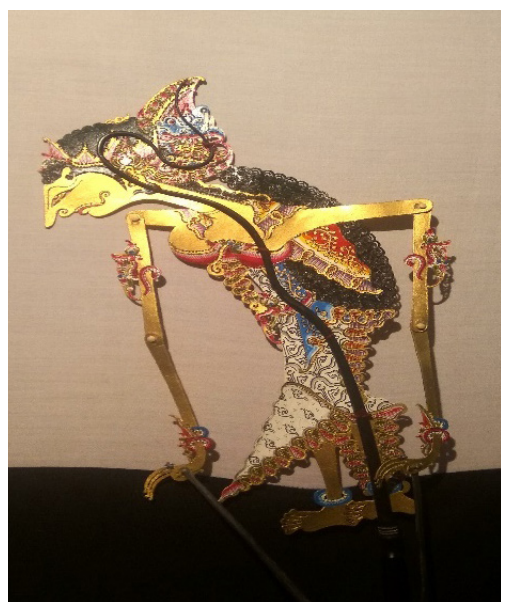

Gambar 5. Dewi Citrawati koleksi Jurusan Pedalangan ISI Yogyakarta. (Foto: Joko Laras Moyo, 2017)
Pengkarya menemukan wayang baku tokoh Prabu Citragada koleksi R. Bima Slamet Raharja, maka pengkarya membuat tokoh Prabu Citragada dengan ciri-ciri sebagai berikut. Muka ndhangak, gembleng, mata gabah-an, hidung walimiring, mulut salitan, memakai mahkota pogogan, kalung ulur-ulur, gelang tangan calumpringan, gelang kaki ngangrangan dan kelat bahu naga pangngangrang. Boneka wayang Prabu Citragada dapat dilihat pada gambar 6.

d. Prabu Darmawasesa

Prabu Darmawasesa adalah salah satu raja pelamar yang ditolak oleh Dewi Citrawati. Dalam karya ini Prabu Darmawasesa berwatak nggelèlèng dan ndugal seperti raja sabrang gagah.

Boneka wayang Darmawasesa sejauh pengamatan pengkarya belum ditemukan wayang bakunya, maka pemilihan wayang tersebut berdasarkan hasil wawancara dengan Ki Cerma Sutejo. Adapun bentuk dan ciri-cirinya

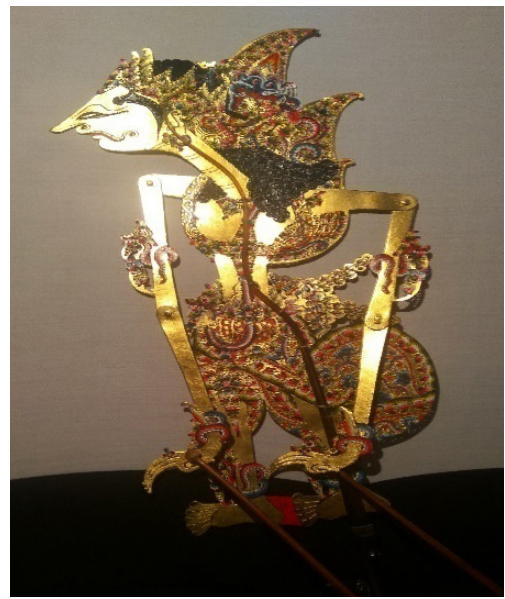

Gambar 6. Prabu Citragada koleksi Joko Laras Moyo. (Foto: Joko Laras Moyo, 2017)

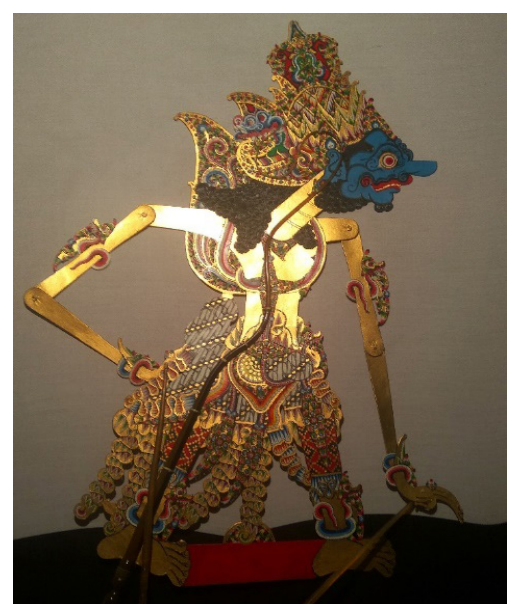

Gambar 7. Prabu Darmawasésa koleksi Jurusan Pedalangan ISI Yogyakarta. (Foto: Joko Laras Moyo, 2017) 
yaitu: wayang gagahan, mata plelengan, muka langak, mulut gusèn, mahkota raja, dan memakai praba. Boneka wayang Prabu Darmawasésa dapat dilihat pada gambar 7 .

e. Patih Suwanda

Patih Suwanda adalah Patih di Negara Maespati. Dalam karya ini Patih Suwanda berperan sebagai penasehat Prabu Harjunasasrabahu dan Patih Negara Maespati.

Adapun bentuk dan ciri-ciri tokoh Patih Suwanda sebagai berikut: muka luruh, mata gabahan, mulut salitan, jamang, gelung sapit urang, sumping sorèng pati. Boneka wayang Patih Suwanda dapat dilihat pada gambar 8 .

f. Prabu Dasamuka

Prabu Dasamuka adalah raja di Negara Ngalengka. Pada karya-karya yang lain digambarkan tokoh Prabu Dasamuka saat marah akan berwujud kepala sepuluh dan tangan dua puluh. Namun, pada karya ini

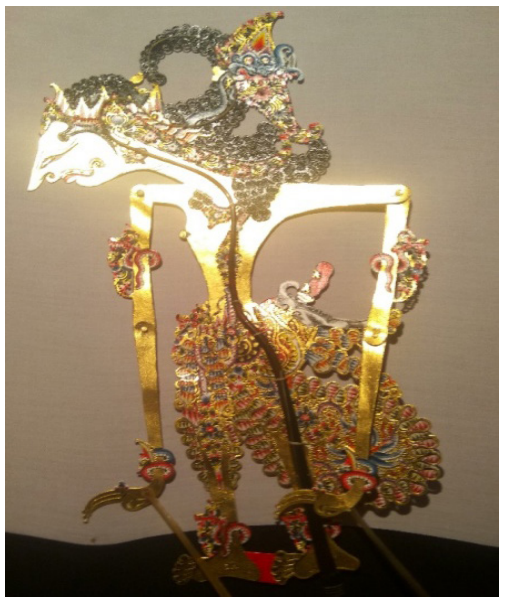

Gambar 8. Patih Suwanda koleksi Joko Laras Moyo. (Foto: Joko Laras Moyo, 2018)

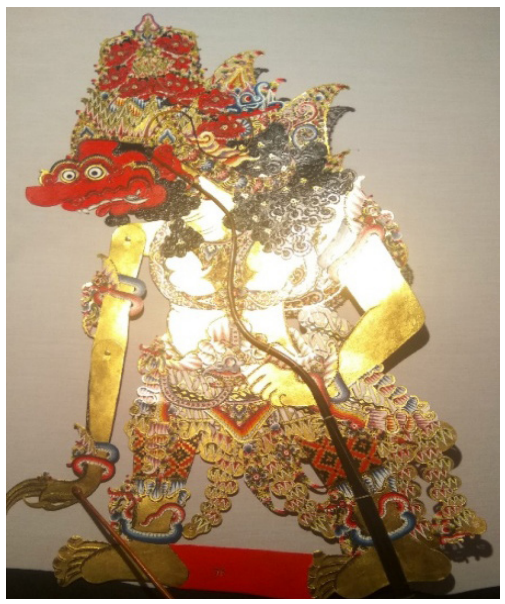

Gambar 9. Prabu Dasamuka Tiwikrama koleksi Joko Laras Moyo. (Foto: Joko Laras Moyo, 2018) pengkarya akan mewujudkan tokoh Prabu Dasamuka bermuka sepuluh dan tangan dua. Hal ini dikarenakan untuk memudahkan pengkarya dalam memainkan saat berperang melawan Harjunasasrabahu.

Adapun bentuk boneka wayang sebagai berikut: wayang gagahan, bermuka merah dan bermuka rasaksa sepuluh, memiliki taring, mata plelengan, memakai mahkota raja dan memakai praba. Boneka wayang Prabu Dasamuka dapat dilihat pada gambar 9.

g. Begawan Jamadagni

Begawan Jamadagni adalah ayah Ramabargawa, seorang brahmana sakti dari pertapan Arga Sekar. Diceritakan dalam karya ini Jamadagni mendapat hasutan dari samaran Prabu Dasamuka.

Boneka wayang Jamadagni sejauh pengamatan pengkarya belum ditemukan wayang bakunya, maka pemilihan wayang

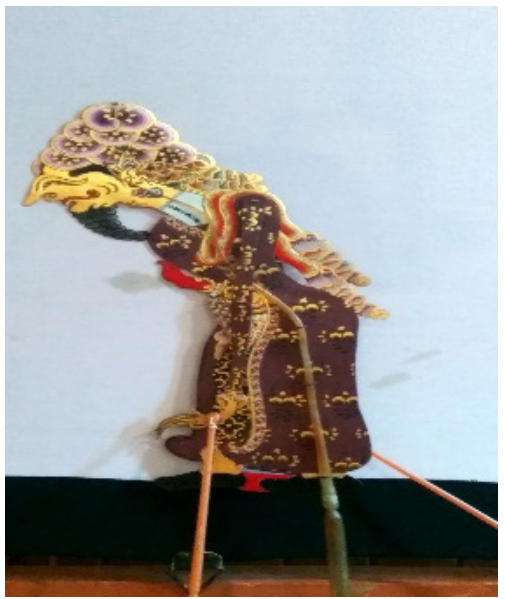

Gambar 10. Begawan Jamadagni koleksi Jurusan Pedalangan, ISI Yogyakarta. (Foto: Joko Laras Moyo, 2017)

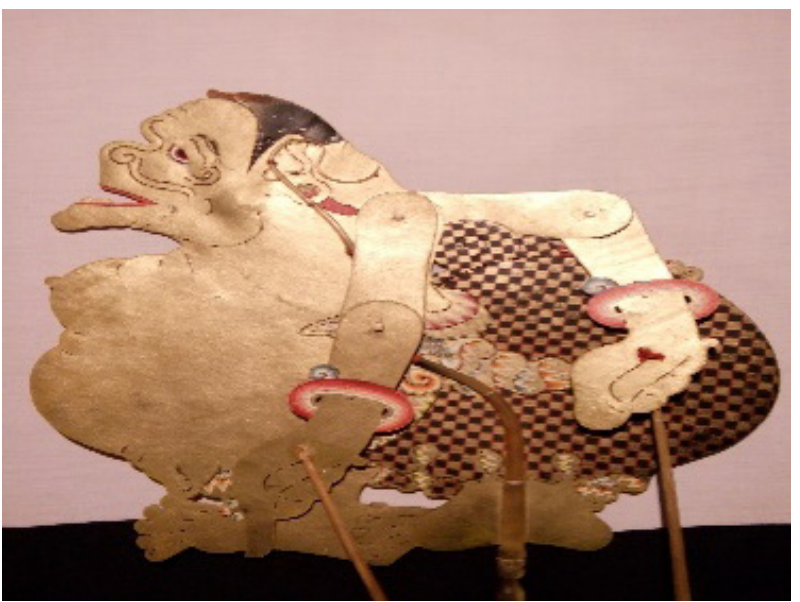

Gambar 11. Semar koleksi Jurusan Pedalangan, ISI Yogyakarta. (Foto: Joko Laras Moyo, 2017) 
tersebut berdasarkan hasil wawancara dengan $\mathrm{Ki}$ Cerma Sutejo. Bentuk wayang adalah Pendhita, muka luruh, mata kiyer, memakai jubah dan surban. Boneka wayang Prabu Jamadagni dapat dilihat pada gambar 10 .

h. Semar

Semar adalah tokoh punakawan. Dalam karya ini pengkarya menampilkan Semar sebagai pamomong Suwanda. Adapun bentuk dan ciricirinya yaitu: mata rèmbèsan, tubuh pendek dan gemuk, memakai anting-anting lombok dan mengunakan kain motif polèng. Boneka wayang Semar dapat dilihat pada gambar 11.

i. Brahala

Brahala adalah penggambaran ketika Prabu Harjunasasrabahu bertiwikrama. Adapun ciricirinya sebagai berikut : berukuran besar, muka rasaksa dua mata plelengan, mulut ngablak dengan gigi dan taring. Boneka wayang Brahala dapat dilihat pada gambar 12 .

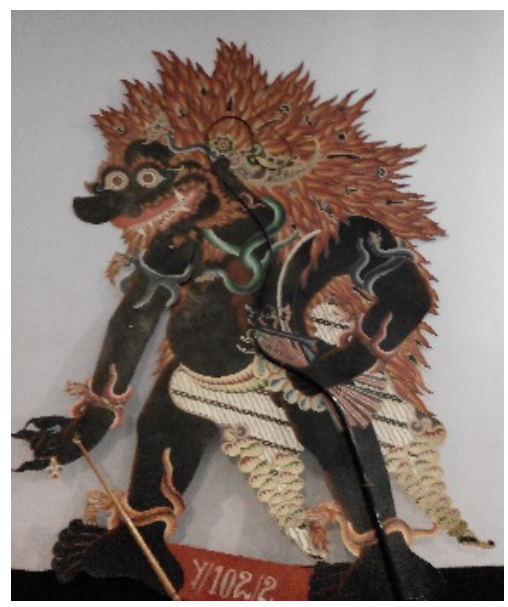

Gambar 12. Brahala koleksi Jurusan Pedalangan ISI Yogyakarta. (Foto: Joko Laras Moyo, 2017)

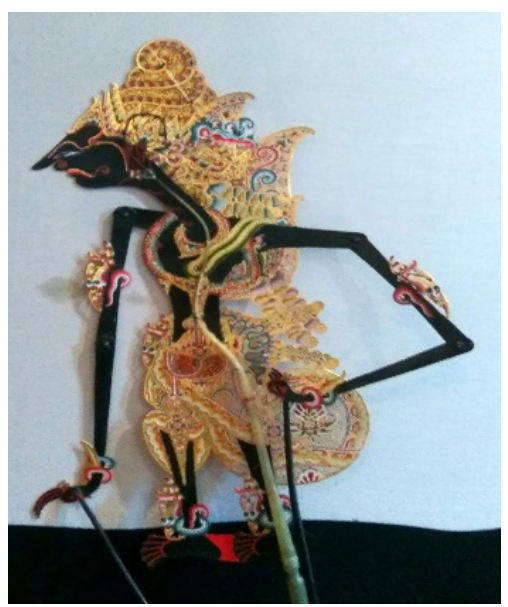

Gambar 13. Bathara Wisnu Murti koleksi Jurusan Pedalangan ISI Yogyakarta. (Foto: Joko Laras Moyo, 2017)

\section{j. Bathara Wisnu Murti}

Bathara Wisnu Murti adalah dewa penguasa Kahyangan Untara Segara. Dalam karya ini diceritakan Batara Wisnu Murti menitis di tubuh Harjunasasrabahu, kemudian oncat karena tugasnya telah selesai. Adapun bentuk dan ciri-cirinya sebagai berikut: memakai mahkota oncit, muka ndhangak, mata berbentuk liyepan, tubuh berwarna hitam, dan memakai mahkota oncit, sampir dan praba. Boneka wayang Bathara Wisnu Murti dapat dilihat pada gambar 13 .

k. Bathara Basuki

Bathara Basuki adalah dewa yang menitis pada tubuh Prabu Baladewa atau tokoh yang berumur panjang. Tokoh yang dititisi Bathara Basuki biasanya berumur panjang. Dalam karya ini Bathara Basuki menitis pada tubuh Ramabargawa. Adapun bentuk dan ciri-cirinya yaitu: memakai mahkota oncit, muka ndhangak

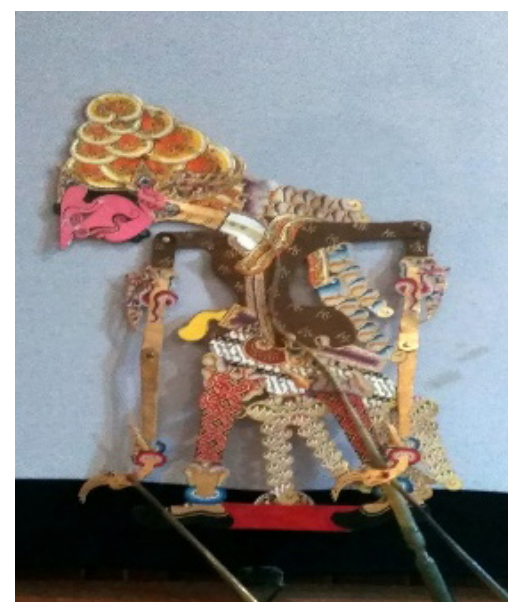

Gambar 14. Bathara Basuki koleksi Jurusan Pedalangan

ISI Yogyakarta. (Foto: Joko Laras Moyo, 2017)

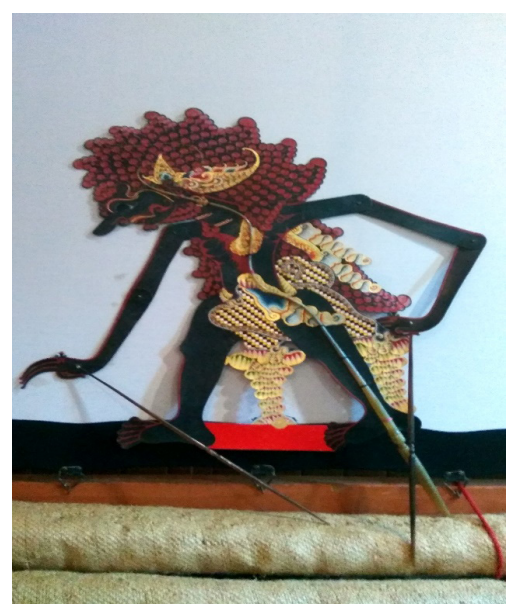

Gambar 15. Ramabargawa koleksi Jurusan Pedalangan ISI Yogyakarta. (Foto: Joko Laras Moyo, 2017) 
bermuka merah muda, mata kedhelèn, memakai sampir. Boneka wayang Bathara Basuki dapat dilihat pada gambar 14 .

1. Ramabargawa

Ramabargawa adalah anak bungsu Begawan Jamadagni dan Dewi Renuka. Dalam karya ini Ramabargawa dikisahkan marah kepada Prabu Harjunasasrabahu karena telah membunuh ayahnya. Ramabargawa menantang Harjunasasrabahu dan kemudian berperang.

Adapun bentuk wayang Ramabargawa dan ciri-cirinya sebagai berikut: tubuh tinggi besar, warna kulit hitam, polatan luruh, mata thelengan, hidung bentulan, mulut mingkem, memiliki kumis dan jenggot, memakai sampir. Boneka wayang Ramabargawa dapat dilihat pada gambar 15 .

\section{Penutup}

Lakon Brubuh Maèspati merupakan sanggit dari lakon-lakon yang menceritakan kisah Harjunasasrabahu, Dewi Citrawati, Suwanda, dan Dasamuka. Karya ini merupakan interpretasi ulang nilai kesetiaan yang terdapat dalam tiga lakon wayang kulit purwa yang dicermati yaitu Sumantri Ngènggèr, Dasamuka Gladhak, dan Bedhah Maèspati.

Interpretasi ulang nilai kesetiaan ini kemudian diwadahi dalam Lakon Brubuh Maèspati yang disajikan dalam pakeliran tradisi Yogyakarta. Lakon Brubuh Maèspati ini dikemas dalam pakeliran padat dengan durasi waktu dua setengah jam.

Lakon Brubuh Maèspati ini diharapkan dapat menambah khasanah sanggit-sanggit lakon yang menceritakan kisah-kisah tentang kerajaan Maespati.

\section{Kepustakaan}

a. Acuan

Mangkunegara VII, K.G.P.A.A., 1965. Serat Pedhalangan Ringgit Purwa Jilid III. Yogyakarta: U.P Indonesia Yogya.

Mudjanattistomo. dkk. 1977. Pedhalangan Ngayogyakarta Jilid I. Yogyakarta: Yayasan Habirandha.
Poespaningrat, Pranoedjoe. 2008. Nonton Wayang Dari Berbagai Pakeliran. Yogyakarta: Kedaulatan Rakyat.

Prasetya, Hanggar Budi. 2004. "Muter Taman Sriwedari: Tafsir Mangkunegara IV dan Ki Manteb Sudarsono". Ekspresi. Jurnal Penelitian dan Penciptaan Seni. Volume 11. Tahun 4: 169-190. Yogyakarta : ISI Yogyakarta.

Satoto, Sudiro. 1985. Wayang Kulit Purwa Makna dan Struktur Dramatiknya. Proyek Penelitian dan Pengkajian Kebudayaan Nusantara

Sindusastra. 1932. Serat Harjuna Sasrabahu Jilid $I V$. Batawisentrem: Balai Pustaka.

Sunardi D.M., 1982. Arjuna Sasrabahu. Jakarta : Balai Pustaka.

Wahyudi, Aris. 2011. "Bima dan Drona Dalam Lakon Dewa Ruci ditinjau dari analisis Strukturalisme Levi-Strauss”. (Desertasi) Universitas Gadjah Mada

Wiyata, Cerma Suparman. 1985. Balungan Lakon Versi Mbah Jayeng Taryono. Manuskrip

\section{b. Audio-Visual}

Asmoro, Purbo Ki. 2012. Sumantri Ngenger https:// youtu.be/AqFRXgz6jlc

Hadiprayitno, Timbul Ki. 2010. Wisnu Ratu mp3: 06-07

Kuncara, Catur Benyek Ki. 2016. Dasamuka Gladhak. Video kaset.

Margiono, Ki. 2016. Brubuh Maespati. Rekaman Mp3 Koleksi RRI Yogyakarta.

Nartosabdo, Ki. 1970. Suwanda Gugur. https:// youtu.be/6m5XVa42FLg.

Sudarsono, Manteb Ki. 2004. Sumantri Ngenger. https://youtu.be/_lFFvtZ-4OY.

\section{c. Narasumber}

Ki Cerma Setedjo. (69 tahun). Seniman dalang senior Yogyakarta beralamat di Gedong Kuning, Bantul, Yogyakarta.

Ki Sugati. (67 tahun). Seniman dalang senior Yogyakarta beralamat di Mbalangan, Seyegan, Sleman, Yogyakarta.

Ki Margiono.(68 tahun). Seniman dalang senior Yogyakarta beralamat di Kowen, Timbulharjo Sewon, Bantul, Yogyakarta. 